\title{
Layered Double Hydroxides as Effective Adsorbents for U(VI) and Toxic Heavy Metals Removal from Aqueous Media
}

\author{
G. N. Pshinko \\ Institute of Colloid and Water Chemistry of the National Academy of Sciences of Ukraine, 42 Vernadsky Boulevard., \\ Kyiv 03680, Ukraine \\ Correspondence should be addressed to G. N. Pshinko; pshinko@ukr.net
}

Received 31 May 2013; Revised 16 September 2013; Accepted 26 September 2013

Academic Editor: Vladyslav V. Goncharuk

Copyright (c) 2013 G. N. Pshinko. This is an open access article distributed under the Creative Commons Attribution License, which permits unrestricted use, distribution, and reproduction in any medium, provided the original work is properly cited.

Capacities of different synthesized $\mathrm{Zn}, \mathrm{Al}$-hydrotalcite-like adsorbents, including the initial carbonate $\left[\mathrm{Zn}_{4} \mathrm{Al}_{2}(\mathrm{OH})_{12}\right] \cdot \mathrm{CO}_{3} \cdot 8 \mathrm{H}_{2} \mathrm{O}$ and its forms intercalated with chelating agents (ethylenediaminetetraacetic acid (EDTA), diethylenetriaminepentaacetic acid (DTPA), and hexamethylenediaminetetraacetic acid (HMDTA)) and heat-treated form $\mathrm{Zn}_{4} \mathrm{Al}_{2} \mathrm{O}_{7}$, to adsorb uranium(VI) and ions of toxic heavy metals have been compared. Metal sorption capacities of hydrotalcite-like adsorbents have been shown to correlate with the stability of their complexes with the mentioned chelating agents in a solution. The synthesized layered double hydroxides (LDHs) containing chelating agents in the interlayer space are rather efficient for sorption purification of aqueous media free from $\mathrm{U}(\mathrm{VI})$ irrespective of its forms of natural abundance (including water-soluble bi- and tricarbonate forms) and from heavy metal ions. $\left[\mathrm{Zn}_{4} \mathrm{Al}_{2}(\mathrm{OH})_{12}\right] \cdot$ EDTA. $n \mathrm{H}_{2} \mathrm{O}$ is recommended for practical application as one of the most efficient and inexpensive synthetic adsorbents designed for recovery of both cationic and particularly important anionic forms of U(VI) and other heavy metals from aqueous media. Carbonate forms of LDHs turned out to be most efficient for recovery of $\mathrm{Cu}$ (II) from aqueous media with $\mathrm{pH}_{0} \geq 7$ owing to precipitation of $\mathrm{Cu}$ (II) basic carbonates and $\mathrm{Cu}$ (II) hydroxides. Chromate ions are efficiently adsorbed from water only by calcinated forms of LDHs.

\section{Introduction}

Nuclear power engineering is still a potentially hazardous industry worldwide now, which is evidenced by two largest nuclear accidents which occurred in Ukraine and Japan. Uranium mining and processing plants and heat-power engineering facilities add to a list of environmentally hazardous enterprises providing for such negative consequences of their operation as the inevitable pollution of the environment with anionic and cationic radioactive nuclides ( $\mathrm{U}_{\text {natural }},{ }^{226} \mathrm{Ra},{ }^{230} \mathrm{Th},{ }^{210} \mathrm{~Pb}$, and ${ }^{210} \mathrm{Po}$ ) and toxic heavy metals (HM). A prosperous progress in the nuclear industry should be reliably safe, that is, secured on high performance technologies of environmental protection against radioactive nuclides and other heavy metals. Therefore, the issues of environmental protection and rehabilitation are particularly relevant. $\mathrm{U}(\mathrm{VI})$ is a most challenging natural radioactive nuclide to be recovered from waste water of uranium-processing plants since it is this radioactive nuclide that adds most to the overall activity accounting for up to $90 \%$ of this activity. Furthermore, this radionuclide features high complexing ability and forms soluble carbonate complexes, $\mathrm{UO}_{2}\left(\mathrm{CO}_{3}\right)_{2}{ }^{2-}$ and $\mathrm{UO}_{2}\left(\mathrm{CO}_{3}\right)_{3}{ }^{4-}$, at $\mathrm{pH}$ characteristic of natural and waste waters resulting in high migration of its compounds in the environment [1].

Methods of purification of large volumes of water, including coagulation and adsorption methods involving natural cationexchangers, show low efficiency, in particular, when anionic forms of toxicants are present. In such cases, selective synthetic, preferably, inorganic adsorbents characterised with sufficiently high radiation resistance are used. Therefore, generation of inexpensive, efficient, and selective sorption materials designed for the extraction of toxic metals, in particular, in the anionic forms, is a problem of the most immediate interest.

Layered double hydroxides (LDHs) built of positively charged brucite-like layers linked by exchangeable anions are rather promising in this context $[2,3]$. Inorganic hydrotalcite 
adsorbents containing carbonate anions in the interlayer space may be successfully used for sorption of cationic forms of uranyl ions from aqueous media $[4,5]$. However, sorption of uranyl ions with such sorbents is substantially reduced in presence of $\mathrm{HCO}_{3}{ }^{-}$and $\mathrm{CO}_{3}{ }^{2-}$ in aqueous solutions.

LDHs with chelating ligands in the interlayer space are efficient enough to extract toxic complex-forming metals [6$8]$. Increase in the length of methylene chain in ethylenediaminetetraacetic acid (EDTA) homologues to $n \geq 6$ ( $n$ is the number of methylene groups) reduces the chelating effect and probability of ring closure. Therefore, the stability constants of the most normal metal chelate complexes with hexamethylenediaminetetraacetic acid (HMDTA) are lower than the stability constants of similar complexes with EDTA [9]. In contrast, diethylenetriaminepentaacetic acid (DTPA), being a potential ligand with an increased number of amine and carboxyl groups, forms more stable, mononuclear complexes than EDTA, with the most complex-forming metals. Moreover, such a chelating agent features higher specificity, in particular, to large cations (including actinides and lanthanides).

This work is aimed at studying $\mathrm{U}(\mathrm{VI})$ and HM sorption capacity of calcinated forms of $\mathrm{Zn}, \mathrm{Al}-\mathrm{LDH}$ s and $\mathrm{Zn}, \mathrm{Al}$ LDHs, containing different chelating agents in the interlayer space, with chelating agents having similar structure, which differ by the stability of their metal complexes in solution.

In this work, we have studied LDHs intercalated with chelating agents (chelate forms $\mathrm{Zn}, \mathrm{Al}-\mathrm{L}$ ) EDTA $\left(\left[-\mathrm{CH}_{2}-\mathrm{N}-(\mathrm{COOH})_{2}\right]_{2}\right), \quad$ DTPA $\quad\left(\left[-\left(\mathrm{CH}_{2}\right)_{4}-(\mathrm{NH})_{3}-\right.\right.$ $\left.\left.(\mathrm{COOH})_{5}\right]\right)$, HMDTA $\left(\left[-\left(\mathrm{CH}_{2}\right)_{3}-\mathrm{N}-(\mathrm{COOH})_{2}\right]_{2}\right), \mathrm{CO}_{3}{ }^{2-}$ ions (carbonate form $\mathrm{Zn}, \mathrm{Al}-\mathrm{CO}_{3}$ ), and calcinated form $\mathrm{Zn}_{4} \mathrm{Al}_{2} \mathrm{O}_{7}$, that may be used to recover $\mathrm{U}(\mathrm{VI})$ and heavy metals ( $\mathrm{Ni}(\mathrm{II}), \mathrm{Co}(\mathrm{II}), \mathrm{Pb}(\mathrm{II}), \mathrm{Cu}(\mathrm{II})$, and $\mathrm{Cr}(\mathrm{VI})$ ) from aqueous media.

\section{Methods}

The following reagents were used in the work: $\mathrm{UO}_{2}\left(\mathrm{SO}_{4}\right)_{2} \cdot 3 \mathrm{H}_{2} \mathrm{O}, \mathrm{CuSO}_{4} \cdot 5 \mathrm{H}_{2} \mathrm{O}, \mathrm{Pb}\left(\mathrm{NO}_{3}\right)_{2}, \mathrm{NiSO}_{4} \cdot 7 \mathrm{H}_{2} \mathrm{O}$, $\mathrm{CoSO}_{4} \cdot 7 \mathrm{H}_{2} \mathrm{O}, \mathrm{K}_{2} \mathrm{CrO}_{4}$, EDTA, HMDTA, and DTPA. Efficiency of U(VI) and HM extraction with different forms of LDHs was studied by using a model water, and the ionic strength $(I)$ was adjusted with $\mathrm{NaClO}_{4}$. Besides that, waste water of a uranium-processing plant with $\mathrm{pH} \approx 8$ and increased salt content $\left(1.5 \mathrm{~g} / \mathrm{dm}^{3}\right)$ was used. Concentrations of certain ions in such waters were as follows $\left(\mathrm{mg} / \mathrm{dm}^{3}\right)$ : $\mathrm{HCO}_{3}{ }^{-}>250, \mathrm{CO}_{3}{ }^{2-} \approx 30, \mathrm{SO}_{4}{ }^{2-}>450, \mathrm{Ca}^{2+} \approx 170$, and $\mathrm{Na}^{+} \approx 240[10]$.

$\mathrm{U}(\mathrm{VI})$ and HM were adsorbed under static conditions with continuous shaking for $1 \mathrm{~h}$; the volume of the aqueous phase was $50 \mathrm{~cm}^{3}$ and the weights of adsorbent samples ranged from $0.05 \mathrm{~g} / \mathrm{dm}^{3}$ to $6.00 \mathrm{~g} / \mathrm{dm}^{3}$ with $C_{\mathrm{Me}}=1$. $10^{-4} \mathrm{M}$. After adsorption equilibrium was achieved, aqueous phase was separated by centrifuging (at $5000 \mathrm{rpm}$ ), and equilibrium concentration of $\mathrm{U}(\mathrm{VI})$ complex with arsenazo III was determined in a strongly acidic medium $\left(5 \mathrm{M} \mathrm{HNO}_{3}\right)$; concentration of $\mathrm{Cr}(\mathrm{VI})$ complex with diphenylcarbazide was determined by spectrophotometry $[11,12]$, and concentration of heavy metals was determined by using C-115-M1 atomic absorption spectrophotometer at the wavelength of $\lambda=$ $232.0 \mathrm{~nm}$ for $\mathrm{Ni}(\mathrm{II}), \lambda=240.7 \mathrm{~nm}$ for $\mathrm{Co}(\mathrm{II}), \lambda=283.3 \mathrm{~nm}$ for $\mathrm{Pb}(\mathrm{II})$, and $\lambda=324.7 \mathrm{~nm}$ for $\mathrm{Cu}(\mathrm{II})$.

The values of metal sorption $\left(a_{s}, \mu \mathrm{mol} / \mathrm{g}\right)$ and the degree of purification (DP, \%) were calculated according to the formulae

$$
a_{s}=\left(C_{0}-C_{\mathrm{eq}}\right) \frac{V}{m}, \quad \mathrm{DP}=\frac{\left(C_{0}-C_{\mathrm{eq}}\right)}{C_{0}} \cdot 100,
$$

where $C_{0}$ and $C_{\mathrm{eq}}$ are initial and equilibrium concentrations of metals, $\mu \mathrm{mol} / \mathrm{dm}^{3} ; V$ is aqueous phase volume, $\mathrm{dm}^{3} ; m$ is weight of mineral, $\mathrm{g}$.

\section{Results and Discussion}

3.1. Synthesis and Analysis of the Chemical Composition of Different Forms of $\mathrm{Zn}, \mathrm{Al}-\mathrm{LDH}$ s. The parameters of synthesis of $\mathrm{Zn}, \mathrm{Al}-\mathrm{CO}_{3}, \mathrm{Zn}_{4} \mathrm{Al}_{2} \mathrm{O}_{7}$, and $\mathrm{Zn}_{4} \mathrm{Al}_{2}$-L hydrotalcite-like adsorbents were optimised $[13,14]$. Chelate forms of adsorbents were synthesized in three stages: first stage synthesis of $\left[\mathrm{Zn}_{4} \mathrm{Al}_{2}(\mathrm{OH})_{12}\right] \cdot \mathrm{CO}_{3} \cdot n \mathrm{H}_{2} \mathrm{O}\left(\mathrm{Zn}, \mathrm{Al}-\mathrm{CO}_{3}\right)$, second obtaining $\mathrm{Zn}_{4} \mathrm{Al}_{2} \mathrm{O}_{7}$ of synthesized $\mathrm{Zn}, \mathrm{Al}-\mathrm{CO}_{3}$ via its heat treatment at $450^{\circ} \mathrm{C}$ for 1 to $2 \mathrm{~h}$, and the third stage synthesis of chelate forms of $\mathrm{Zn}, \mathrm{Al}-\mathrm{L}$ via interaction of mixed oxide $\mathrm{Zn}_{4} \mathrm{Al}_{2} \mathrm{O}_{7}$ with aqueous solutions of certain chelating agents containing ammonium hydroxide. In order to avoid formation of byproducts, $\mathrm{pH}$ of the initial solution of a chelating agent was adjusted with $20 \%$ ammonia to $\mathrm{pH}$ ranging 2.5 to 8 prior adding mixed oxide $\mathrm{Zn}_{4} \mathrm{Al}_{2} \mathrm{O}_{7}$. The obtained products were washed with 5 to 7 portions of hot deionized water on a glass filter and dried at $50^{\circ} \mathrm{C}$ in an oven for $12 \mathrm{~h}$.

Chelate forms of LDHs-Zn,Al-L were synthesized in accordance with the following scheme:

$$
\begin{aligned}
& \mathrm{Zn}_{4} \mathrm{Al}_{2} \mathrm{O}_{7}+\mathrm{H}_{x} \mathrm{~L}+(5+n) \mathrm{H}_{2} \mathrm{O} \\
& \quad \longrightarrow\left[\mathrm{Zn}_{4} \mathrm{Al}_{2}(\mathrm{OH})_{12}\right] \cdot \mathrm{H}_{x-2} \mathrm{~L} \cdot n \mathrm{H}_{2} \mathrm{O}
\end{aligned}
$$

The synthesized products were identified by using chemical analysis of synthesized samples of LDHs after dissolution of adsorbents in diluted (1:1) hydrochloric acid and adding deionized water (free of $\mathrm{CO}_{2}$ ) to solutions obtained. $\mathrm{Zn}$ and $\mathrm{Al}$ contents in an adsorbent sample were determined by using atomic absorption spectrophotometry and total organic carbon (contents of chelating agents) by chromatography [15]. Empirical chemical formulas of LDHs were determined on basis of the results of analysis of molecular ratio of $\mathrm{Zn}$ (II) and $\mathrm{Al}(\mathrm{III})$ and chelating agents. The content of $\mathrm{OH}^{-}$ions was determined accounting for the neutrality of adsorbents, and the quantity of molecules of crystallization water was determined on the basis of both thermal and thermogravimetric analyses and by calculating the difference between total weight of adsorbent and its individual components. Values matched in a good way. The results of analysis suggest the following chemical formula of synthesized adsorbents: $\left[\mathrm{Zn}_{4} \mathrm{Al}_{2}(\mathrm{OH})_{12}\right] \mathrm{L} \cdot 8 \mathrm{H}_{2} \mathrm{O}$. 


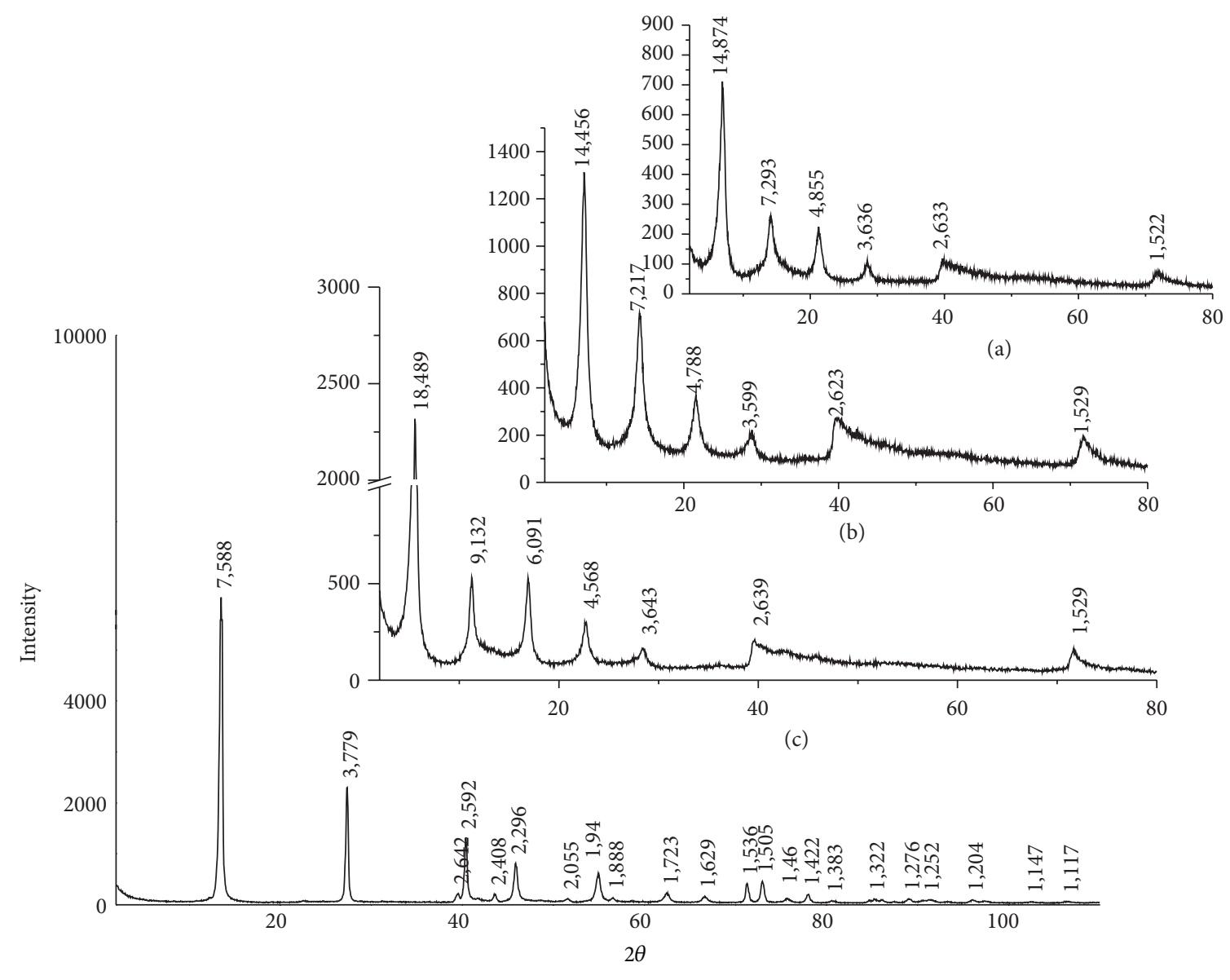

(d)

FIgURE 1: X-ray diffraction images of hydrotalcite adsorbents: (a) Zn,Al-EDTA, (b) Zn,Al-DTPA, (c) Zn,Al-HMDTA, and (d) Zn,Al-CO 3 .

3.2. X-Ray Investigation of the Adsorbents. Phase composition of $\mathrm{Zn}_{4} \mathrm{Al}_{2}(\mathrm{OH})_{12} \cdot \mathrm{CO}_{3} \cdot n \mathrm{H}_{2} \mathrm{O}$ and $\mathrm{Zn}, \mathrm{Al}-\mathrm{L}$ adsorbents was determined by using DRON-2.0 X-ray diffractometer with filtered cobalt emission. Figure 1 shows X-ray diffraction images of $\mathrm{Zn}, \mathrm{Al}-\mathrm{CO}_{3}$ and chelate forms (Zn,Al-L). All synthetic sorbents obtained in this work were single-phase ones. The calculated lattice parameters are within experimental error identical with the literature data for $\mathrm{Zn}$,Al-hydrotalcite phase composition $\left[\mathrm{Zn}_{4} \mathrm{Al}_{2}(\mathrm{OH})_{12}\right] \cdot \mathrm{CO}_{3} \cdot n \mathrm{H}_{2} \mathrm{O}$ (Figure $1(\mathrm{~d})$ ) with a $\mathrm{Zn}: \mathrm{Al}$ ratio of $2: 1$ [16]. The first four diffraction reflections in the X-ray diffraction image of Zn,Al-EDTA (Figure 1(a)) form a close-to-integer series making it possible to consider them basic 003, 006, 009, and 00.12 reflections of a hydrotalcite-like structure. Spacing between brucite-like layers is $0.975 \mathrm{~nm}$. It has been calculated as the mean of the positions of 006,009 , and 00.12 reflections $\left(2 d_{006}+3 d_{009}+\right.$ $\left.4 d_{00.12}\right) / 3=1.455 \mathrm{~nm}$ minus the depth of a hydrotalcite layer $(0.48 \mathrm{~nm})$. Two broad diffraction lines at high Bragg angle $(2 \theta)$ seen in the X-ray diffraction images are also attributed to $\mathrm{Zn}, \mathrm{Al}-\mathrm{EDTA}$.

Five diffraction lines forming an integer series-003, $006,009,00.12$, and 00.15 - are seen in the initial portion of Zn,Al-HMDTA X-ray diffraction image (Figure 1(c)). The value of the first basal reflection is calculated as the arithmetic mean: $\left(2 d_{006}+3 d_{009}+4 d_{00.12}+5 d_{00.15}\right) / 3=$ $1.825 \mathrm{~nm}$. Apart from these basal diffraction reflections, the $\mathrm{X}$-ray image contains also a nonsymmetric diffraction line at $0.2639 \mathrm{~nm}$ with a tail extending to larger angles and diffraction line 110 corresponding to interplanar spacing of $0.1529 \mathrm{~nm}$. Such X-ray image is typical for layered hydrotalcite structures. It shows that an intercalation of HMDTA ions into the interlayer space causes an increase in the value of the first basal diffraction reflection characteristic of $\mathrm{Zn}, \mathrm{Al}$ hydrotalcite $(2: 1)$ from 0.764 to $1.825 \mathrm{~nm}$. Subtraction of the depth of the brucite-like layer gives the value of the depth of the interlayer space occupied with HMDTA anions equal to $1.345 \mathrm{~nm}$.

X-ray diffraction image of Zn,Al-DTPA contains 4 intense diffraction peaks forming a close-to-integer series of reflections corresponding to $14.46,7.22,4.79$, and $3.60 \AA$. This makes it possible, on one hand, to assign the observed diffraction lines to basal reflections 001 and, on the other hand, to show that intercalation of DTPA in the interlayer space of an adsorbent structure causes an increase in the interplanar spacing to $9.66 \AA$. According to [17], the estimated length of DTPA anion is approximately $14 \AA$ along N-C-N$\mathrm{C}$ chain and substantially exceeds the value of the interplanar spacing of the obtained hydrotalcite intercalated with DTPA 
anions. Thus, we may conclude that DTPA anions are inclined to the plane parallel to hydrotalcite layers.

The arrangement of intercalated EDTA anions between the charged brucite-like layers is still under discussion in the literature. On the basis of X-ray studies, we have found that vertical anions of chelating agents with the different lengths of $(-\mathrm{N}-\mathrm{C} \cdots \mathrm{C}-\mathrm{N}-)$ chain are inclined at identical angles to the basal plane of a brucite-like layer in all studied adsorbents intercalated with chelating agents. According to the model described in [6], ligand anions are arranged in a manner that makes $(-\mathrm{N}-\mathrm{C}-\mathrm{C}-\mathrm{N}-)$ chain perpendicular to brucite layers. According to [7], such vertical arrangement of ligands should provide for the interplanar spacing of $1.12 \mathrm{~nm}$ in hydrotalcite layers. The observed lower interplanar spacing $(0.977 \mathrm{~nm})$ suggests that EDTA ions are inclined to the brucite-like layers. If we assume that the geometries of anions having the same charge, for example, HMDTA ${ }^{2-}$ and $\mathrm{EDTA}^{2-}$, differ only with the values of lengths of their $(-\mathrm{N}-\mathrm{C} \cdot \mathrm{C}-\mathrm{C}-\mathrm{N}-)$ chains, we can calculate the difference between such lengths along the lines of the same. It has been shown empirically that adding one carbon atom to a paraffin chain lengthens the molecule by $0.126 \mathrm{~nm}$, on average [18]. Therefore, in case of vertical arrangement of similarly charged ligand anions in layered double hydroxides intercalated with chelating agents, the difference between values of interplanar spacing in brucite-like layers should be $0.126 \times 4=0.504 \mathrm{~nm}$. The actually observed value is lower: $1.825-1.455=0.37 \mathrm{~nm}$. Such lower value confirms the inclined arrangement of intercalated anions of chelating agents in the interlayer space, and should the molecules of EDTA, HMDTA, and DTPA be tilted at the same angle to the basal plane of a brucite-like layer, such angle is $\alpha \approx 47.2^{\circ}$ $(\arcsin \alpha=0.37 \mathrm{~nm} / 0.504 \mathrm{~nm})$.

3.3. Uranium(VI) and HM Sorption with Different LDH Forms. Figure 2 illustrates the influence of $\mathrm{pH}$ on $\mathrm{U}(\mathrm{VI})$ and $\mathrm{Cu}$ (II) sorption with different forms of $\mathrm{Zn}$,Al-LDHs.

Figure 2 shows that maximum values of $U(V I)$ sorption (Figure 2(a)) are achieved in the $\mathrm{pH}$ range of 5 to 10 for $\mathrm{Zn}, \mathrm{Al}$ EDTA, which testifies the high performance of adsorption of not only cationic but also anionic forms of uranium(VI), for example, soluble carbonate anions formed in more basic range of $\mathrm{pH}$ in case of air exposure of an aqueous solution. The virtually full recovery of $\mathrm{Cu}(\mathrm{II})$ (Figure $2(\mathrm{~b})$ ) is observed for $\mathrm{ZnAl}-\mathrm{CO}_{3}$ at $\mathrm{pH}>7$ owing to the precipitation of slightly soluble basic carbonates and, partially, hydroxides.

It is known that $\mathrm{U}(\mathrm{VI})$ is characterized by the formation of highly soluble $\mathrm{UO}_{2}\left(\mathrm{CO}_{3}\right)_{2}{ }^{2-}$ and $\mathrm{UO}_{2}\left(\mathrm{CO}_{3}\right)_{3}{ }^{4-}$ even when the aqueous solution is in contact with air. For $\mathrm{Cu}(\mathrm{II})$ at $\mathrm{pH}>7$, aqueous solution is characterized by formation of poorly soluble hydroxycarbonates and apparently partly hydroxides (Figures 3(a) and 3(b)). Therefore, for U(VI) sorption mechanism is observed by caused complexation on $\mathrm{Zn}, \mathrm{Al}-\mathrm{EDTA}$ and $\mathrm{Zn}, \mathrm{Al}-\mathrm{CO}_{3}$ at $\mathrm{pH}>7$ does remove not $\mathrm{U}(\mathrm{VI})$ practically. For $\mathrm{Cu}(\mathrm{II})$ at $\mathrm{pH}>7$, almost complete is observed deposition on $\mathrm{ZnAl}-\mathrm{CO}_{3}$, and in more acidic media more efficient sorption is observed on Zn,Al-EDTA (Table 1).
Sorption performance of Zn,Al-HMDTA and Zn,AlEDTA in the purification of waste water having the aforementioned composition from U(VI) was analyzed for different doses of adsorbents (Figure 4). It has been shown that Zn,AlHMDTA provides for $66 \%$ to $68 \%$ degree of purification (adsorbent dose $-1 \mathrm{~g} / \mathrm{dm}^{3}$ ) and Zn,Al-EDTA for $94 \%$ to $98 \%$ degree of purification; when the adsorbent dose increases to $6 \mathrm{~g} / \mathrm{dm}^{3}$, the degree of purification is higher and almost equal for both adsorbents ( $93 \%$ to $98 \%$ ).

Moreover, sorption isotherms show that sorption capacity of $\mathrm{Zn}, \mathrm{Al}-\mathrm{DTPA}$ is higher in the range of low concentrations of $\mathrm{U}(\mathrm{VI})$ in solution (the corresponding isotherm is almost linear, and the rate of recovery of $\mathrm{U}(\mathrm{VI})$ is $99.9 \%$ ) than the sorption capacity of $\mathrm{Zn}, \mathrm{Al}-\mathrm{EDTA}$ and $\mathrm{Zn}, \mathrm{Al}-\mathrm{CO}_{3}$ under the same conditions (Figure 5). This is due to a more strong binding of $\mathrm{U}(\mathrm{VI})$ with DTPA than with EDTA and $\mathrm{CO}_{3}{ }^{2-}$ ions; maximum values of sorption perfectly correlate with the stability of corresponding complexes; $a_{\max }, \mu \mathrm{mol} / \mathrm{g}$, are equal: 131.6, 153.9, 166.7 for Zn,Al-CO $\mathrm{CO}_{3}, \mathrm{Zn}, \mathrm{Al}-\mathrm{HMDTA}$, and $\mathrm{Zn}, \mathrm{Al}-$ HMDTA, respectively (note that isotherm; were described by Freundlich and Langmuir equations in the initial region of the isotherms both equations describe the sorption of metals by these sorbents satisfactorily; the maximum values of sorption were found using the Langmuir equations).

At higher concentrations of U(VI) its sorption is substantially higher on Zn,Al-EDTA and Zn,Al-DTPA owing to coprecipitation of uranium(VI) on the surface of the adsorbent leading to actually full recovery of uranium (irrespective of its concentration in a solution) on this adsorbent $[11,15]$.

To evaluate the efficiency of $\mathrm{U}(\mathrm{VI})$ recovery on $\mathrm{Zn}, \mathrm{Al}$ $\mathrm{LDH}$ adsorbents intercalated with chelating agents, we have studied the effects of the concentration of carbonate ions in water (Figure 6) $[13,14,19]$. Figure 6 shows that an increase in concentration of carbonate ions in water results in a sharp decrease in $\mathrm{U}(\mathrm{VI})$ sorption with synthesized forms of hydrotalcite $\left(\mathrm{Zn}, \mathrm{Al}-\mathrm{CO}_{3}\right)$; that is, carbonate ions in the interlayer space of hydrotalcite are not exchanged with the carbonate forms of $\mathrm{U}(\mathrm{VI})$ in solution and no extraction of carbonate forms of radioactive nuclide occurs. In case of $\mathrm{Zn}, \mathrm{Al}-\mathrm{EDTA}$, increased concentrations of $\mathrm{CO}_{3}{ }^{2-}$ ions cause actually no reduction of the degree of sorption owing to the formation of more strong $\mathrm{U}(\mathrm{VI})$ complexes with chelating anions of EDTA in the interlayer space. The results obtained show that this adsorbent may be used for the purposes of purification of uranium-containing water with increased levels of carbonate and hydrocarbonate ions characteristic of natural water.

Furthermore Figure 6 confirms that the sorbent Zn,AlEDTA is highly effective for the sorption of $\mathrm{U}(\mathrm{VI})$ at high concentrations of $\mathrm{CO}_{3}{ }^{2-}$ ions, which is very important for uranium-processing plants wastewater treatment with high content of carbonates and bicarbonates. It is noteworthy that no complexes of uranium(VI) with hydrocarbonate ions have been found; however, such anions play the key role in the formation of strong carbonate complexes of uranium (VI) owing to a shift of carbon-dioxide equilibrium in presence of metal ions. 


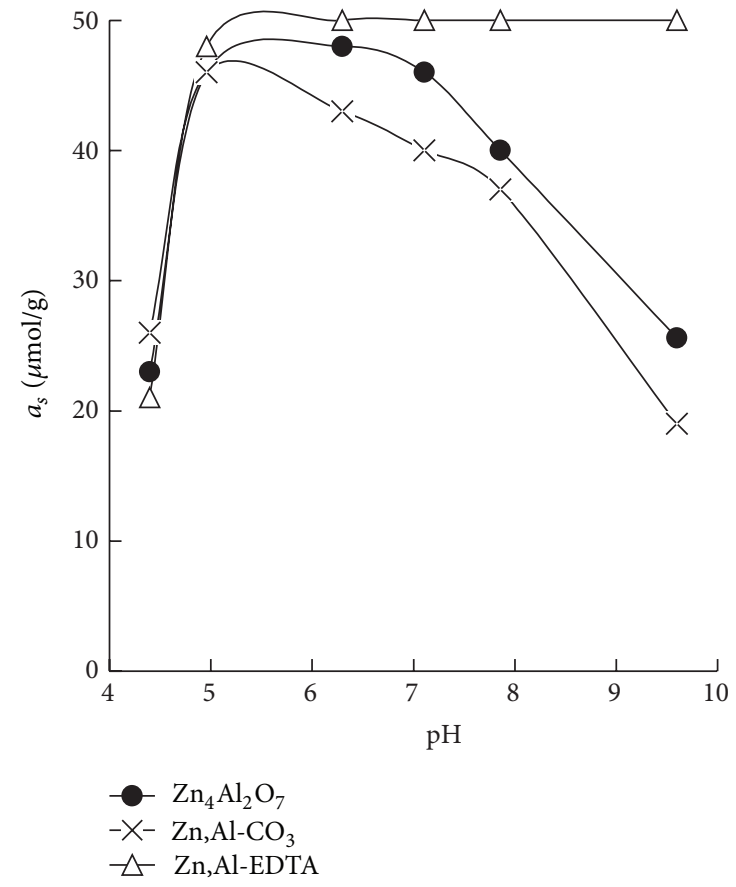

(a)

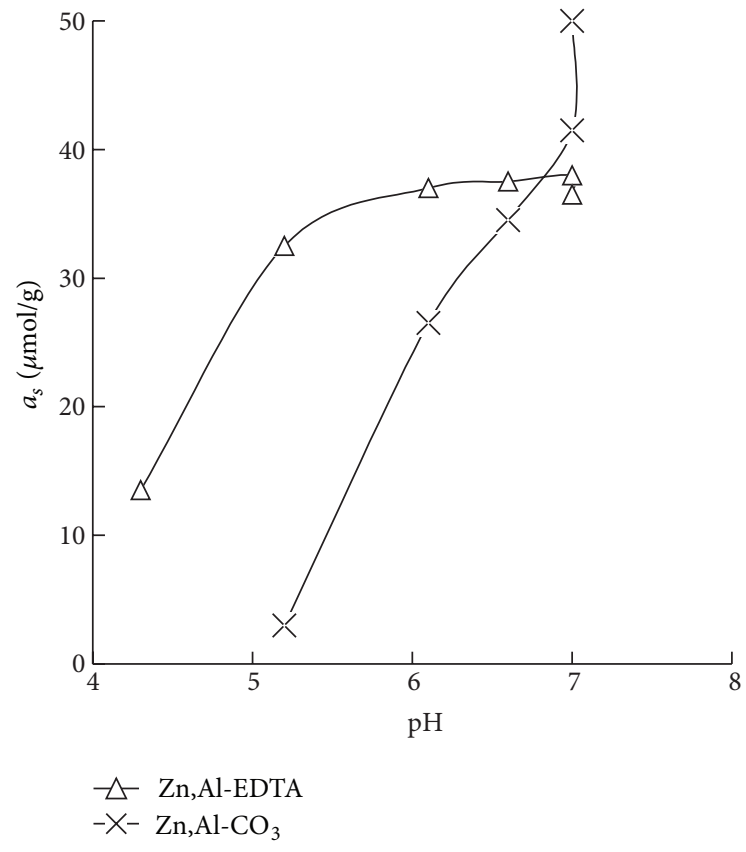

(b)

FIGURE 2: Influence of $\mathrm{pH}_{\text {bal. }}$ on $\mathrm{U}(\mathrm{VI})(\mathrm{a})$ and $\mathrm{Cu}(\mathrm{II})(\mathrm{b})$ sorption with different forms of adsorbents. $C_{\mathrm{U}(\mathrm{VI})}=100 \mu \mathrm{mol} / \mathrm{g}, V_{\text {solution }}=50 \mathrm{~cm}{ }^{3}$, and $m_{\text {adsorbent }}=0.100 \mathrm{~g}$.

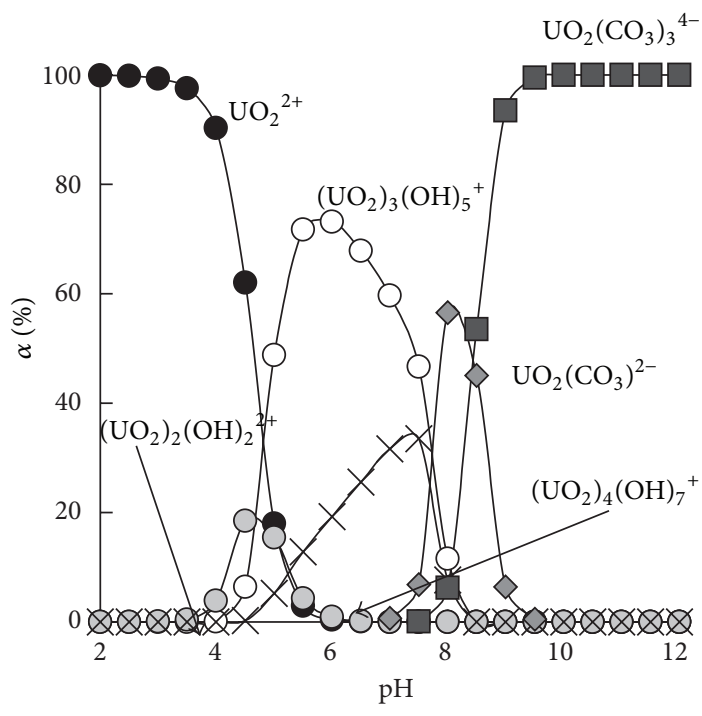

(a)

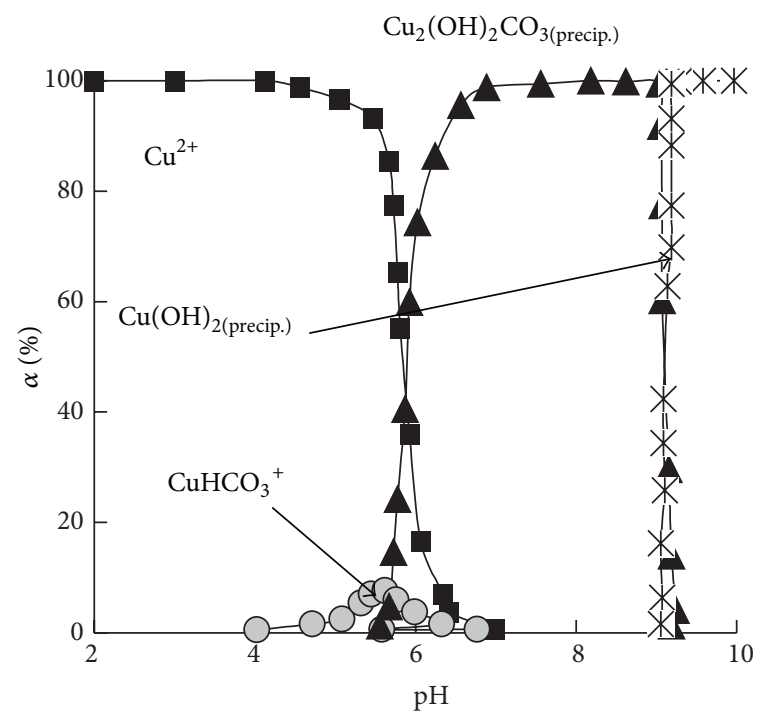

(b)

Figure 3: The forms of U(VI) (a) and $\mathrm{Cu}(\mathrm{II})(\mathrm{b})$ in aqueous solution in the presence of carbonate ions. $C_{\left(\mathrm{co}_{3}^{2-}\right)}=10^{-3} \mathrm{M} ; C_{\mathrm{U}(\mathrm{VI})}=C_{\mathrm{Cu}(\mathrm{II})}=$ $10^{-4} \mathrm{M}$.

TABLE 1: The general stability constants of complex compounds $(\lg \beta)$ and sediment $\left(\lg K_{s}\right)$ formed by sparingly soluble salts and complexes of copper $\left(\lg K_{s}\right)(I=0)$.

\begin{tabular}{|c|c|c|c|}
\hline \multicolumn{2}{|c|}{$\lg \beta$} & \multicolumn{2}{|c|}{$\lg K_{s}$} \\
\hline $\mathrm{OH}^{-}$ & $\mathrm{H}_{4} \mathrm{~L}$-EDTA & $\mathrm{OH}^{-}$ & $\mathrm{CO}_{3}{ }^{2-}$ \\
\hline $\begin{array}{l}\mathrm{Cu}(\mathrm{OH})^{+} 6,0 \\
\mathrm{Cu}_{2}(\mathrm{OH})_{2} 17,1\end{array}$ & $\begin{array}{l}\text { CuL 18,8; CuHL 21,8; } \\
\quad \mathrm{Cu}(\mathrm{OH}) \mathrm{L} 21,2\end{array}$ & $\mathrm{Cu}(\mathrm{OH})_{2} 18,2$ & $\begin{array}{c}\mathrm{Cu}_{2}(\mathrm{OH})_{2} \mathrm{CO}_{3} 42,96 \\
\mathrm{Cu}_{3}(\mathrm{OH})_{2}\left(\mathrm{CO}_{3}\right)_{2} 54,69\end{array}$ \\
\hline
\end{tabular}




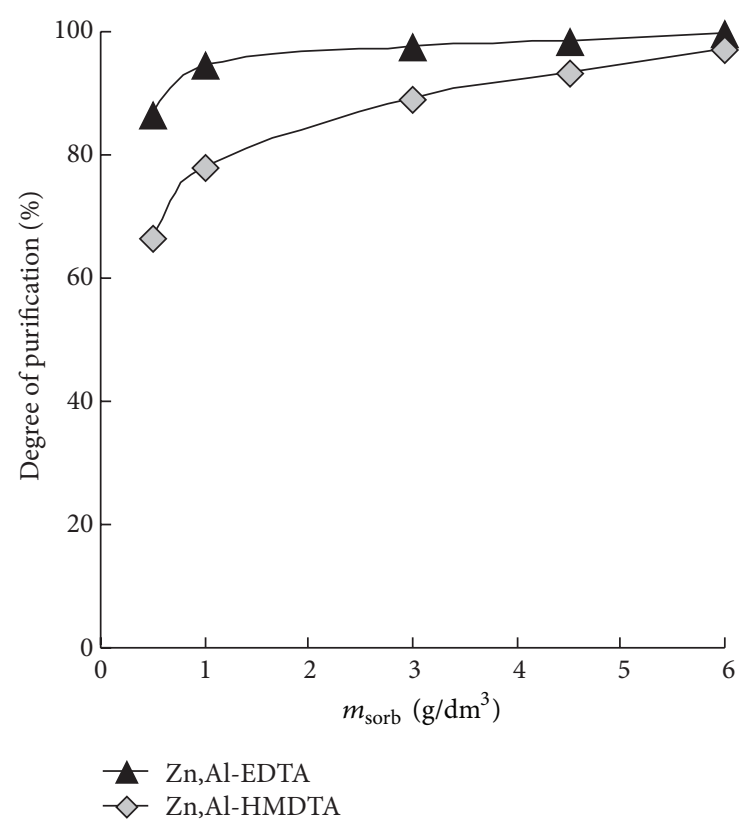

FIGURE 4: Comparative estimation of the recovery efficiencies of $\mathrm{U}(\mathrm{VI})$ from waste water with different forms of $\mathrm{Zn}$, Al-L adsorbents.

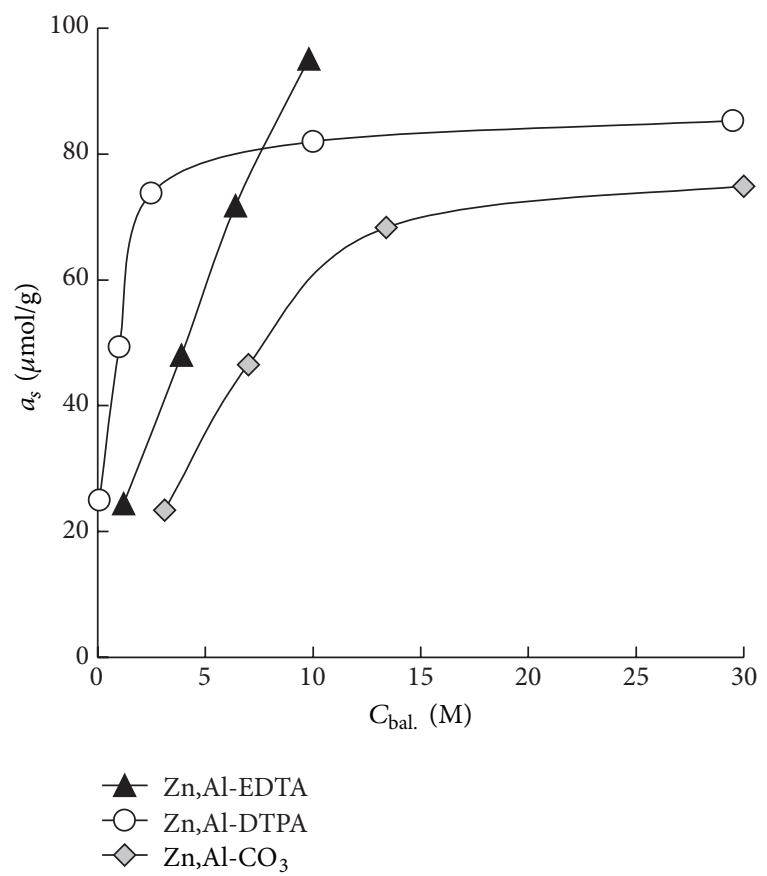

FIGURE 5: U(VI) sorption isotherms for chelate and carbonate forms of adsorbents. $\mathrm{pH}=6.5, V_{\text {solution }}=50 \mathrm{~cm}^{3}$, and $m_{\text {adsorbent }}=0.100 \mathrm{~g}$.

In order to provide for an integral evaluation of the performance of the synthesized adsorbents in the purification of a model solution in deionized water with $I_{\left(\mathrm{NaClO}_{4}\right)}=$ 0.01 and $\mathrm{pH}_{0}=7.7$ and plants wastewater having the composition described in [10], the degree of recovery of $\mathrm{U}(\mathrm{VI})$ has been estimated at the adsorbent doses of $1 \mathrm{~g} / \mathrm{dm}^{3}$

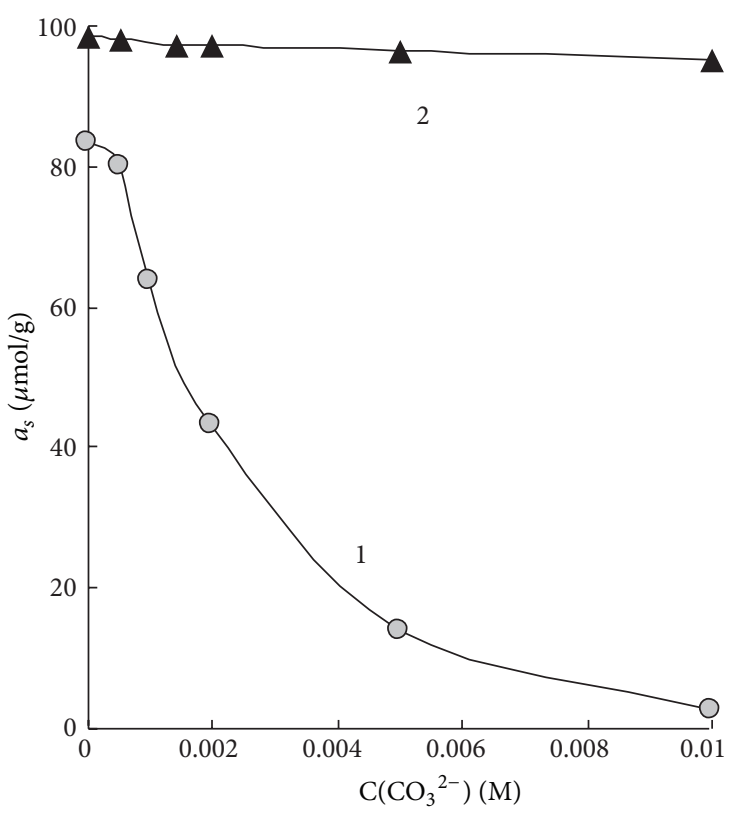

FIGURE 6: Effect of carbonate ion concentration on $\mathrm{U}(\mathrm{VI})$ sorption with different forms of adsorbents: (1) Zn, Al- $\mathrm{CO}_{3}$ and (2) Zn,AlEDTA. $C_{\mathrm{U}(\mathrm{VI})}=1 \cdot 10^{-4} \mathrm{M}, V_{\text {sol. }}=50 \mathrm{~cm}^{3}$, and $m_{\text {ads. }}=0.05 \mathrm{~g}$.

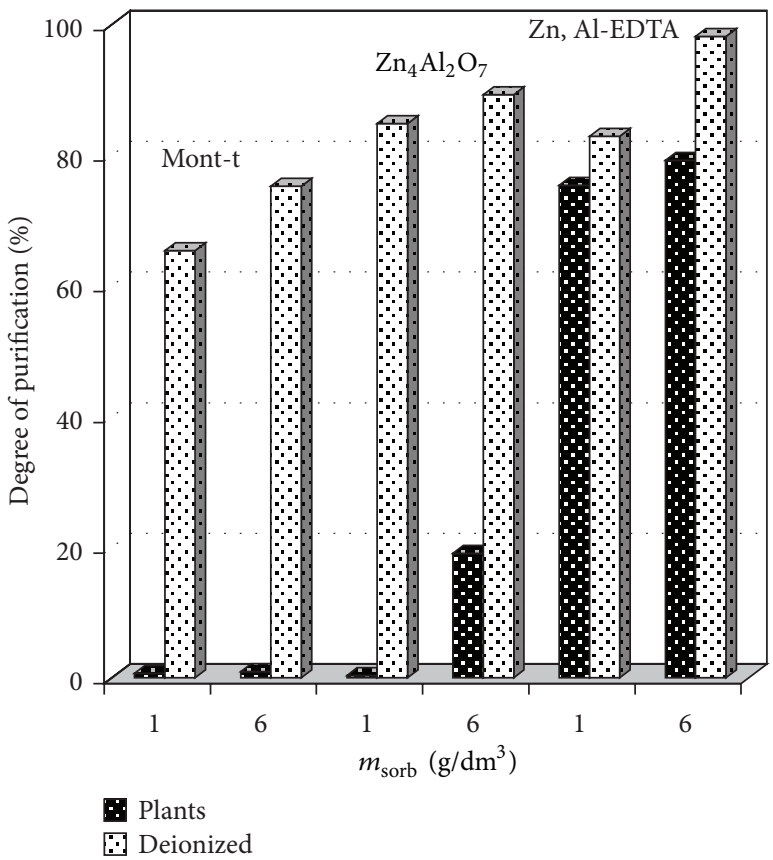

FIgURE 7: Comparative evaluation of the recovery efficiency of $\mathrm{U}(\mathrm{VI})$ compounds from aqueous media with different adsorbents, pH 8. $V_{\text {sol. }}=50 \mathrm{~cm}^{3}$.

and $6 \mathrm{~g} / \mathrm{dm}^{3}$ (Figure 7). The efficiency of $\mathrm{U}(\mathrm{VI})$ recovery with clay mineral montmorillonite having rather high cation exchange capacity of a natural adsorbent of 0.7 mgeqv./g is shown for reference. Figure 7 shows that montmorillonite is actually inefficient $(<1 \%)$ for the purification of plants 


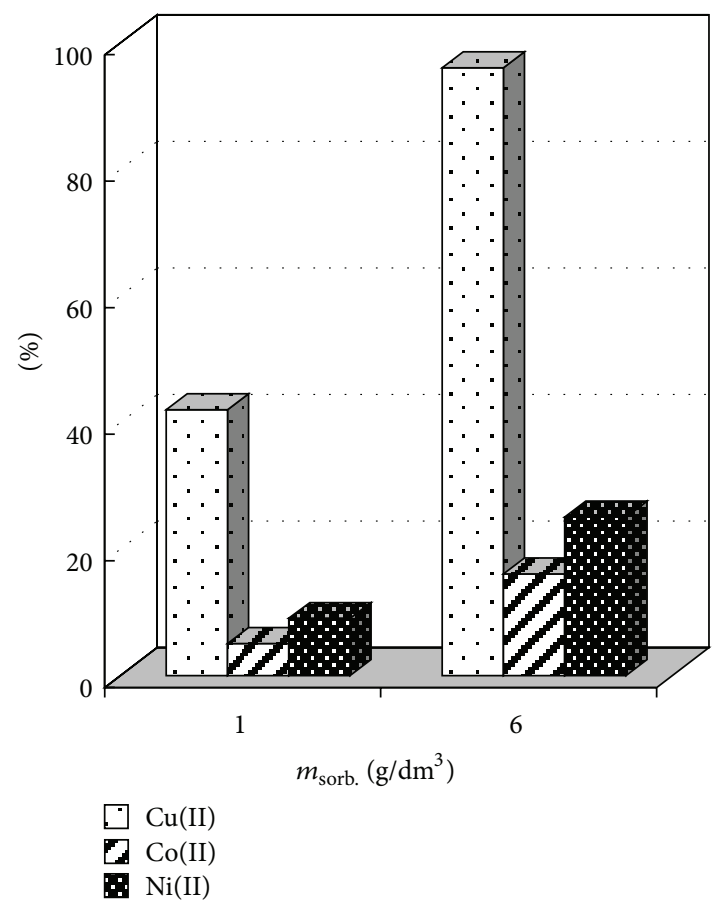

(a)

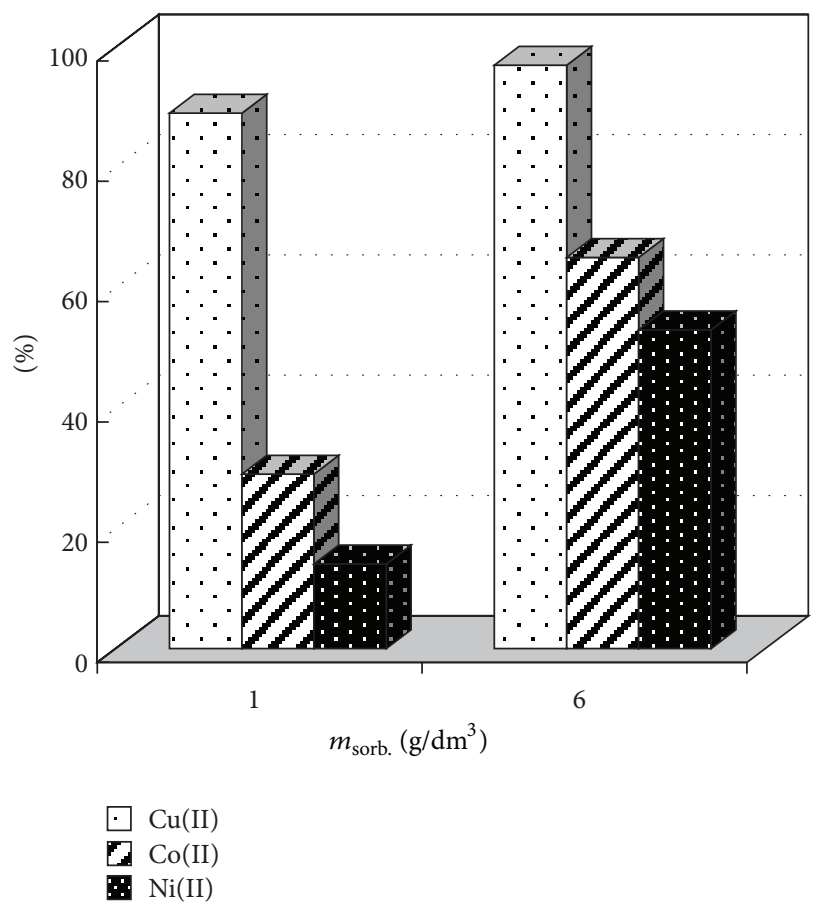

(b)

Figure 8: Influence of the dose of $\mathrm{Zn}, \mathrm{Al}-\mathrm{CO}_{3}$ (a) and $\mathrm{Zn}, \mathrm{Al}-\mathrm{EDTA}$ (b) adsorbents on the degree of purification of aqueous solutions from $\mathrm{Cu}(\mathrm{II}), \mathrm{Ni}(\mathrm{II})$, or $\mathrm{Co}(\mathrm{II}) . \mathrm{I}=0 ; \mathrm{pH}_{0}=3.5$.

wastewater from $\mathrm{U}(\mathrm{VI})$ due to the fact that this adsorbent is present in its anionic carbonate forms at the given $\mathrm{pH}$ value. Heat-treated form of hydrotalcite, $\mathrm{Zn}_{4} \mathrm{Al}_{2} \mathrm{O}_{7}$, in the doses of $1 \mathrm{~g} / \mathrm{dm}^{3}$ and $6 \mathrm{~g} / \mathrm{dm}^{3}$ may provide for $75 \%$ to $85 \%$ rate of recovery of uranium(VI) from the model solution in deionized water, correspondingly, whereas the rate of recovery from plants wastewater is $19.0 \%$ when the adsorbent dose is $6 \mathrm{~g} / \mathrm{dm}^{3}$. Meanwhile, $\mathrm{Zn}, \mathrm{Al}$-EDTA adsorbent features rather high efficiency of purification of both model and wastewater at the levels of $99.9 \%$ and $80 \%$, correspondingly.

Thus, all Zn,Al-L chelate adsorbents are promising in terms of recovery of $\mathrm{U}(\mathrm{VI})$ compounds from aqueous media, including those with increased mineralization, in the broad $\mathrm{pH}$ range.

Efficiency of heavy metal recovery from aqueous media with adsorbents on the basis of LDH has been studied in the systems with adsorbent doses of $1 \mathrm{~g} / \mathrm{dm}^{3}$ and $6 \mathrm{~g} / \mathrm{dm}^{3}$ and $\mathrm{pH}_{0}=3.5$, containing actually no hydrolyzed forms of metals (Figure 8). This figure shows that the degree of purification of water from $\mathrm{Cu}$ (II) with $\mathrm{Zn}, \mathrm{Al}-\mathrm{CO}_{3}$ adsorbent in the dose of $1 \mathrm{~g} / \mathrm{dm}^{3}$ is $42 \%$ and with Zn,Al-EDTA $90 \%$. An increase in the adsorbent dose to $6 \mathrm{~g} / \mathrm{dm}^{3}$ results in actually complete recovery of copper ions with both carbonate form of the adsorbent owing to the precipitation of copper in a form of double salts basic carbonates (increased adsorbent dose results in a more full immobilisation of copper in its basic carbonate form), and EDTA-intercalated form owing to the formation of strong copper complexes with EDTA.
The ionic strength of a solution has actually no effect on $\mathrm{Pb}(\mathrm{II}), \mathrm{Ni}(\mathrm{II}), \mathrm{Co}(\mathrm{II})$, and $\mathrm{Cu}(\mathrm{II})$ sorption with $\mathrm{Zn}, \mathrm{Al}-\mathrm{EDTA}$ testifying to immobilization of metal ions owing to their complex formation with the functional groups of hexadentate ligand (EDTA). Nickel(II) and cobalt(II) sorption on Zn,Al$\mathrm{CO}_{3}$ are substantially lower (by the factor of 2 to 3.5) than on $\mathrm{Zn}, \mathrm{Al}-\mathrm{EDTA}$ at both values of ionic strength [20]. This suggests the dominating mechanism of extraction of such ions on account of complex formation with the chelating ligand of adsorbent.

Chelate forms of adsorbents turn out to be particularly promising also for $\mathrm{Pb}(\mathrm{II})$ and $\mathrm{Cu}(\mathrm{II})$ recovery from aqueous media at $\mathrm{pH}<7$. A comparison of sorption efficiency of $\mathrm{Zn}, \mathrm{Al}-\mathrm{L}$ for $\mathrm{HM}$ recovery from aqueous solutions shows that adsorbent intercalated with DTPA is highly efficient for $\mathrm{Pb}$ (II) recovery, evidently, owing to its increased specificity to large cations.

Unlike the aforementioned heavy metals, chromium(VI) occurs in water only in its anionic form. It is toxic for living organisms, and its maximum allowable concentration in potable water is lower than that of $\mathrm{Cr}$ (III) by an order of magnitude. Sorption recovery of anionic forms of $\mathrm{Cr}(\mathrm{VI})$ from aqueous media is a rather challenging problem. The use of anionic adsorbents may be an appropriate solution [21, 22]. Preliminary studies have shown that chelate and carbonate forms of LDHs are of low efficiency with the rate of recovery of not more than $2 \%$ to $3 \%$. Therefore, we have studied $\mathrm{Cr}$ (VI) sorption from aqueous media by using calcinated forms of LDHs that have underwent heat treatment directly on the day of sorption measurement. 


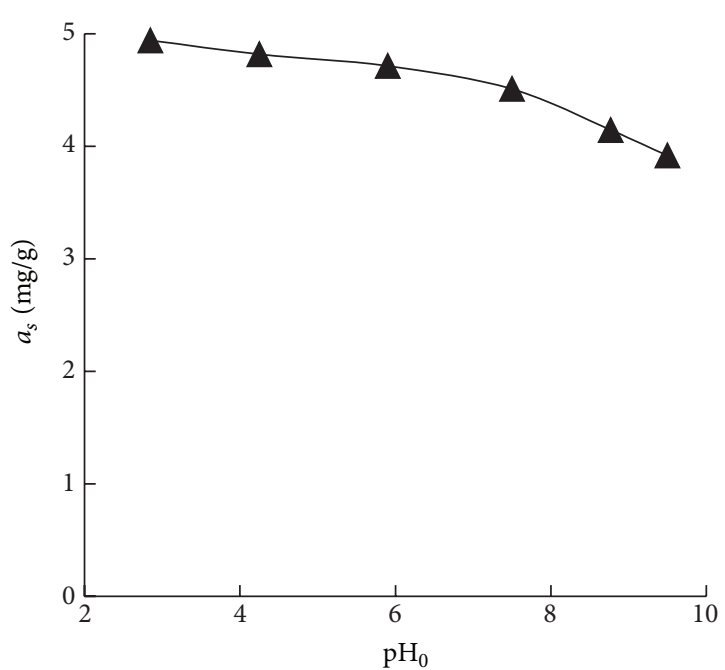

Figure 9: Effects of $\mathrm{pH}$ on $\mathrm{Cr}(\mathrm{VI})$ sorption with $\mathrm{Zn}_{4} \mathrm{Al}_{2} \mathrm{O}_{7}$ from deionized water. $C_{\mathrm{Cr}(\mathrm{VI})}=5.0 \mathrm{mg} / \mathrm{dm}^{3}, m=0.05 \mathrm{~g}$, and $V=50 \mathrm{~cm}^{3}$.

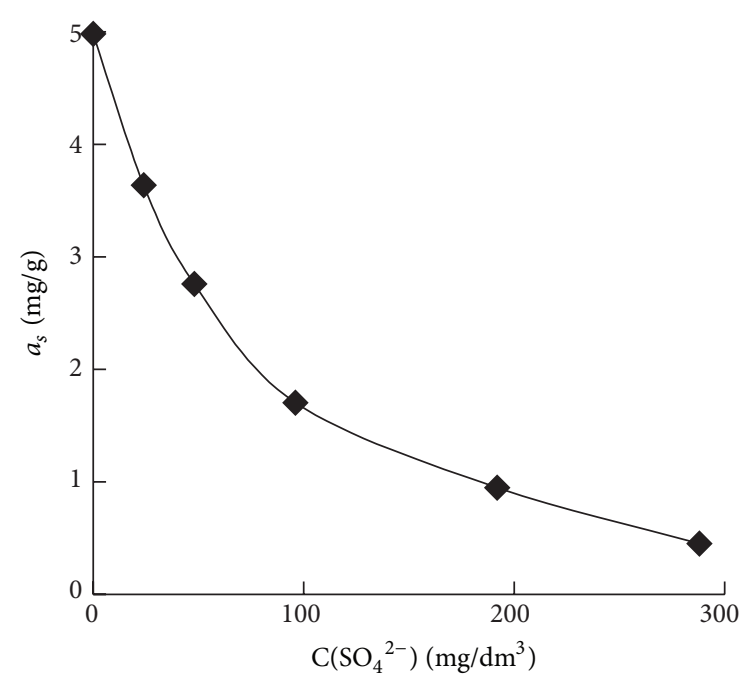

FIgURE 10: Effects of $\mathrm{SO}_{4}{ }^{2-}$ concentration on $\mathrm{Cr}(\mathrm{VI})$ sorption on $\mathrm{Zn}_{4} \mathrm{Al}_{2} \mathrm{O}_{7}$ at $\mathrm{pH}_{0}=5.0 . \mathrm{C}_{\mathrm{Cr}(\mathrm{VI})}=5.0 \mathrm{mg} / \mathrm{dm}^{3}, m=0.05 \mathrm{~g}$, and $V=50 \mathrm{~cm}^{3}$.

Heat-treated $\mathrm{LDH}$ form, $\mathrm{Zn}_{4} \mathrm{Al}_{2} \mathrm{O}_{7}$, placed into an aqueous solution may comprise anions according to the following chemical equation:

$$
\begin{aligned}
& \mathrm{Zn}_{4} \mathrm{Al}_{2} \mathrm{O}_{7}+(7+n) \mathrm{H}_{2} \mathrm{O}+\mathrm{CrO}_{4}{ }^{2-} \\
& \quad \longrightarrow\left[\mathrm{Zn}_{4} \mathrm{Al}_{2}(\mathrm{OH})_{12}\right] \cdot \mathrm{CrO}_{4} \cdot n \mathrm{H}_{2} \mathrm{O}+2 \mathrm{OH}^{-}
\end{aligned}
$$

Heat-treated form of a $\mathrm{LDH}$ is shown in (2) to absorb anions from aqueous media to restore its initial structure, which is confirmed with the results of our X-ray diffraction studies $[4,13]$. It has been found that $\mathrm{pH}_{0}$ values of 3 to 4 are optimal for adsorption (Figure 9), and single-charged anions have less effect on the rate of recovery of chromate ions: they actually cause no reduction in $\mathrm{HCO}_{3}{ }^{-}$sorption in the range of up to $7 \mathrm{mgeqv} . / \mathrm{dm}^{3}$ and $\mathrm{NO}_{3}{ }^{-}$sorption in the range of up to $0.2 \mathrm{M}$, whereas the effects of $\mathrm{SO}_{4}{ }^{2-}$ are more pronounced: sulphate ions in the dose of $30 \mathrm{mg} / \mathrm{dm}^{3}$ reduce the rate of recovery of $\mathrm{Cr}(\mathrm{VI})$ by $20 \%$ (Figure 10 ). The influence of interfering substances on the rate of recovery of chromate ions may be avoided through an increase in the adsorbent weight: actually complete recovery of $\mathrm{Cr}(\mathrm{VI})$ from $1 \mathrm{dm}^{3}$ of water containing $50 \mathrm{mg} / \mathrm{dm}^{3}$ of $\mathrm{SO}_{4}{ }^{2-}$ ions is achieved with the adsorbent weight of $2 \mathrm{~g}$. When the level of sulphate ions is below $20 \mathrm{mg} / \mathrm{dm}^{3}$, the dose of an adsorbent may be reduced to $1 \mathrm{~g} / \mathrm{dm}^{3}$.

\section{Conclusions}

This work suggests that high performance synthetic inorganic adsorbents-layered double hydroxides of zinc and aluminium intercalated with chelating agents-may be used for sorption of cationic and anionic forms of $\mathrm{U}(\mathrm{VI})$ within a technology of purification of highly mineralized water containing carbonate ions. It has been shown for the first time that carbonate forms of layered double hydroxides of $\mathrm{Zn}$ and $\mathrm{Al}$ are more efficient than forms intercalated with EDTA for purification of water with $\mathrm{pH}_{0} \geq 7$ from $\mathrm{Cu}$ (II) owing to the precipitation of slightly soluble compounds, predominantly, basic carbonates and, partially, metal hydroxides on an adsorbent $\left(K_{d}=99,000 \mathrm{~cm}^{3} / \mathrm{g}\right)$. Zn,Al-EDTA is an efficient adsorbent for $\mathrm{Ni}(\mathrm{II}), \mathrm{Co}(\mathrm{II})$, and $\mathrm{Pb}$ (II) sorption via complex formation. The rate of recovery of such elements correlates with the stability constants of their chelate complexes in solution. Only heat-treated (directly prior to sorption) $\mathrm{LDH}$ form, $\mathrm{Zn}_{4} \mathrm{Al}_{2} \mathrm{O}_{7}$, is promising for an efficient recovery of chromate ions.

The optimal conditions have been established for adsorption processes, and the studied adsorbents have been shown to be used as potential adsorbents for the recovery of $\mathrm{U}(\mathrm{VI})$ and other heavy metals from waste water of mining and processing plants and other waters containing toxic metals.

\section{Acknowledgment}

G. N. Pshinko appreciates all kinds of support and advice provided by the Director of the Institute of Colloid and Water Chemistry of the National Academy of Science of Ukraine, a Member of the Academy, Professor V. V. Goncharuk, in carrying out this study.

\section{References}

[1] S. A. Kobets, G. N. Pshinko, and L. N. Puzyrnaya, "Uranium (VI) in natural waters: study of occurrence forms," Journal of Water Chemistry and Technology, vol. 34, no. 6, pp. 277-283, 2012.

[2] F. Cavani, F. Trifirò, and A. Vaccari, "Hydrotalcite-type anionic clays: preparation, properties and applications," Catalysis Today, vol. 11, no. 2, pp. 173-301, 1991.

[3] C. Forano, T. Hibino, F. Leroux, and C. Taviot-Guého, "Layrered double hydroxides," in Handbook of Clay Science, F. Bergaya, B. K. G. Theng, and G. Lagaly, Eds., Development in Clay Science, chapter 13.1, pp. 1021-1095, 2006. 
[4] T. G. Timoshenko, A. A. Kosorukov, G. N. Pshinko, and V. V. Goncharuk, "Calcinated hydrotalcite-a sorbent for purifying uraniferous waters," Journal of Water Chemistry and Technology, vol. 31, no. 4, pp. 250-255, 2009.

[5] S. A. Kulyukhin, E. P. Krasavina, I. V. Gredina, I. A. Rumer, and L. V. Mizina, "Sorption of U(VI) from aqueous solutions on layered double hydroxides of $\mathrm{Mg}, \mathrm{Al}$, and $\mathrm{Nd}$," Radiochemistry, vol. 52, no. 6, pp. 653-661, 2010.

[6] M. R. Pérez, I. Pavlovic, C. Barriga, J. Cornejo, M. C. Hermosín, and M. A. Ulibarri, "Uptake of $\mathrm{Cu}^{2+}, \mathrm{Cd}^{2+}$ and $\mathrm{Pb}^{2+}$ on $\mathrm{Zn}-\mathrm{Al}$ layered double hydroxide intercalated with edta," Applied Clay Science, vol. 32, no. 3-4, pp. 245-251, 2006.

[7] K. A. Tarasov, D. O'Hare, and V. P. Isupov, "Solid state chelation of metals ions by ethylenediamintetraacetate intercalated in a layered double hydroxide," Inorganic Chemistry, vol. 42, pp. 1119-1127, 2003.

[8] I. Pavlovic, M. R. Pérez, C. Barriga, and M. A. Ulibarri, "Adsorption of $\mathrm{Cu}^{2+}, \mathrm{Cd}^{2+}$ and $\mathrm{Pb}^{2+}$ ions by layered double hydroxides intercalated with the chelating agents diethylenetriaminepentaacetate and meso-2,3-dimercaptosuccinate," Applied Clay Science, vol. 43, no. 1, pp. 125-129, 2009.

[9] IUPAC Chemical Data Series-No 22, Stability constants of Metal-Ion Complexes. Part B: Organic Ligands. Complied by D.D. Perrin, Pergamon Press, New York, NY, USA, 1979.

[10] T. G. Timoshenko, A. A. Bogolepov, and G. N. Pshinko, "Treatment of radioactively contaminated waters with an increased content of salts," Journal of Water Chemistry and Technology, vol. 31, no. 1, pp. 46-52, 2009.

[11] A. A. Nemodruk and L. P. Glukhova, "Interaction of Uranium(VI) with Arsenazo III in strongly acid solutions," Journal of Analytical Chemistry, vol. 43, no. 1, pp. 93-98, 1963 (Russian).

[12] Z. Marchenko, Photometric Determination of Elements, Mir Publications, Moscow, Russia, 1971.

[13] G. N. Pshinko, A. A. Kosorukov, L. N. Puzyrnaya, and V. V. Goncharuk, "Layered double hydroxides intercalated with EDTA as effective sorbents for U(VI) recovery from wastewater," Radiochemistry, vol. 53, no. 3, pp. 303-307, 2011.

[14] X. Liang, W. Hou, Y. Xu et al., "Sorption of lead ion by layered double hydroxide intercalated with diethylenetriaminepentaacetic acid," Colloids and Surfaces A, vol. 366, no. 1-3, pp. 50-57, 2010.

[15] A. A. Kosorukov, G. N. Pshinko, L. N. Puzyrnaya, and S. A. Kobetz, "Extraction of U(VI) from aqueous media with layered double hydroxides interacted with chelating agents," Journal of Water Chemistry and Technology, vol. 35, no. 3, pp. 188-202, 2013 (Russian).

[16] I. Pausch, H. H. Lohse, K. Schurmann, and R. Allmann, "Synthesis of disordered and Al-rich hydrotalcite-like compounds," Clays \& Clay Minerals, vol. 34, no. 5, pp. 507-510, 1986.

[17] L. A. Kaplan, "Comparison of high-temperature and persulfate oxidation methods for determination of dissolved organic carbon in freshwaters," Limnology \& Oceanography, vol. 37, no. 5, pp. 1119-1125, 1992.

[18] A. W. Brindley and A. Brown, Crystal Structures of Clay Minerals and Their X-Ray Identification, Mineralogical Society, Berkeley, Calif, USA, 1980.

[19] V. V. Goncharuk, G. N. Pshinko, and L. N. Puzyrnaya, "Sorption-desorption processes in the system of U(VI)-layered double hydroxide intercalated with EDTA," Journal of Water Chemistry and Technology, vol. 34, no. 2, pp. 88-95, 2012 (Russian).
[20] V. V. Goncharuk, L. N. Puzyrnaya, G. N. Pshinko, A. A. Kosorukov, and V. Y. Demchenko, "Removal of Cu(II), Ni(II), and $\mathrm{Co}(\mathrm{II})$ from aqueous solutions using layered double hydroxide intercalated with EDTA," Journal of Water Chemistry and Technology, vol. 33, no. 5, pp. 288-292, 2011 (Russian).

[21] K.-H. Goh, T.-T. Lim, and Z. Dong, "Application of layered double hydroxides for removal of oxyanions: a review," Water Research, vol. 42, no. 6-7, pp. 1343-1368, 2008.

[22] R. L. Goswamee, P. Sengupta, K. G. Bhattacharyya, and D. K. Dutta, "Adsorption of $\mathrm{Cr}(\mathrm{VI})$ in layered double hydroxides," Applied Clay Science, vol. 13, no. 1, pp. 21-34, 1998. 

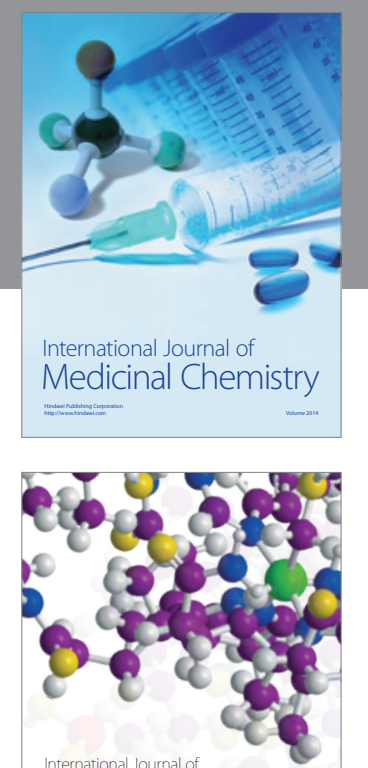

\section{Carbohydrate} Chemistry

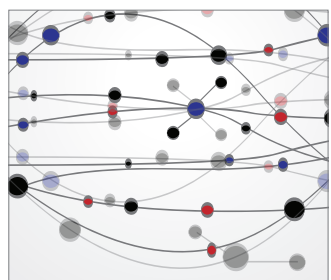

The Scientific World Journal
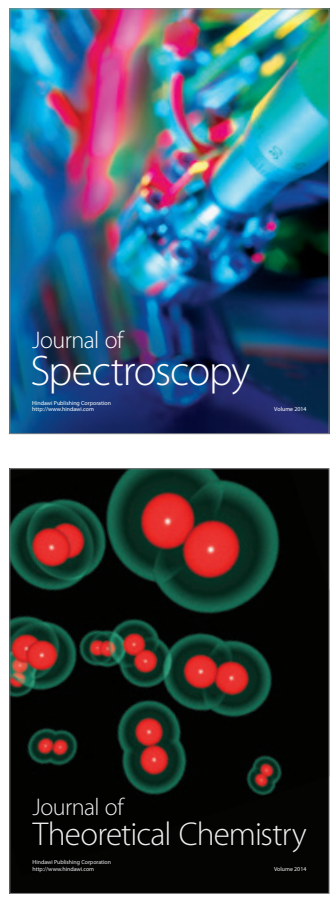
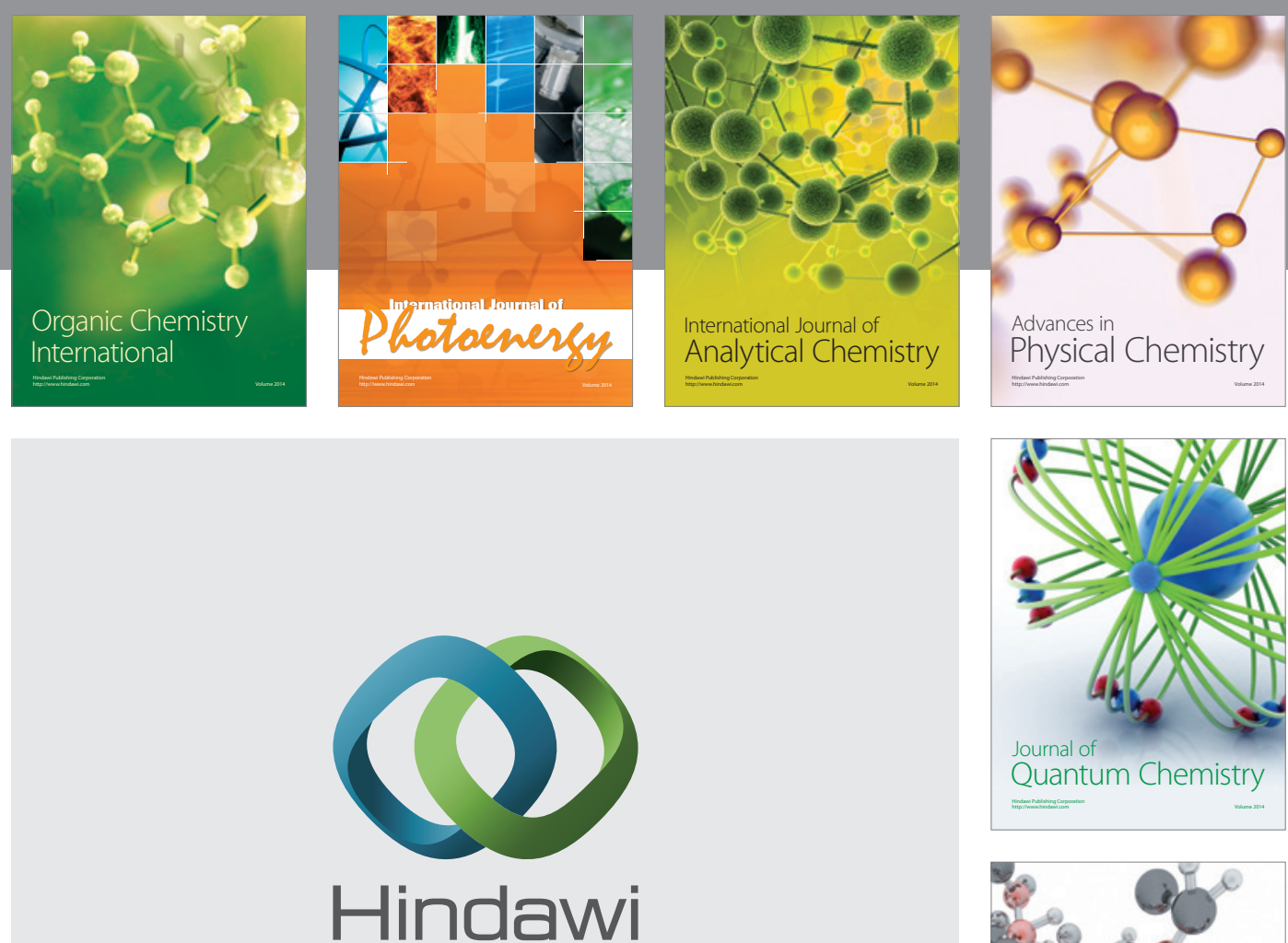

Submit your manuscripts at

http://www.hindawi.com

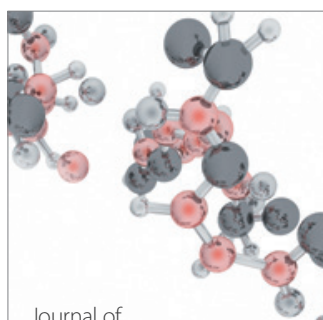

Analytical Methods

in Chemistry

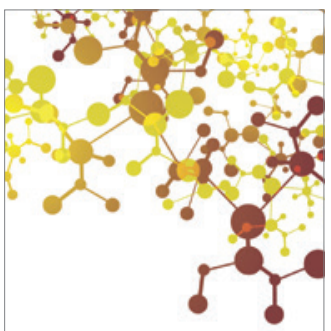

Journal of

Applied Chemistry

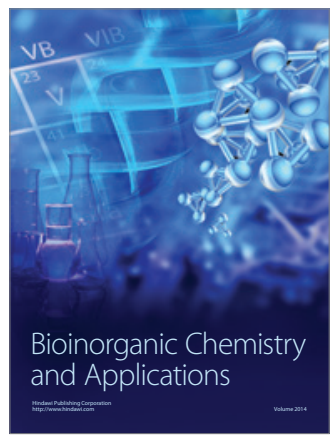

Inorganic Chemistry
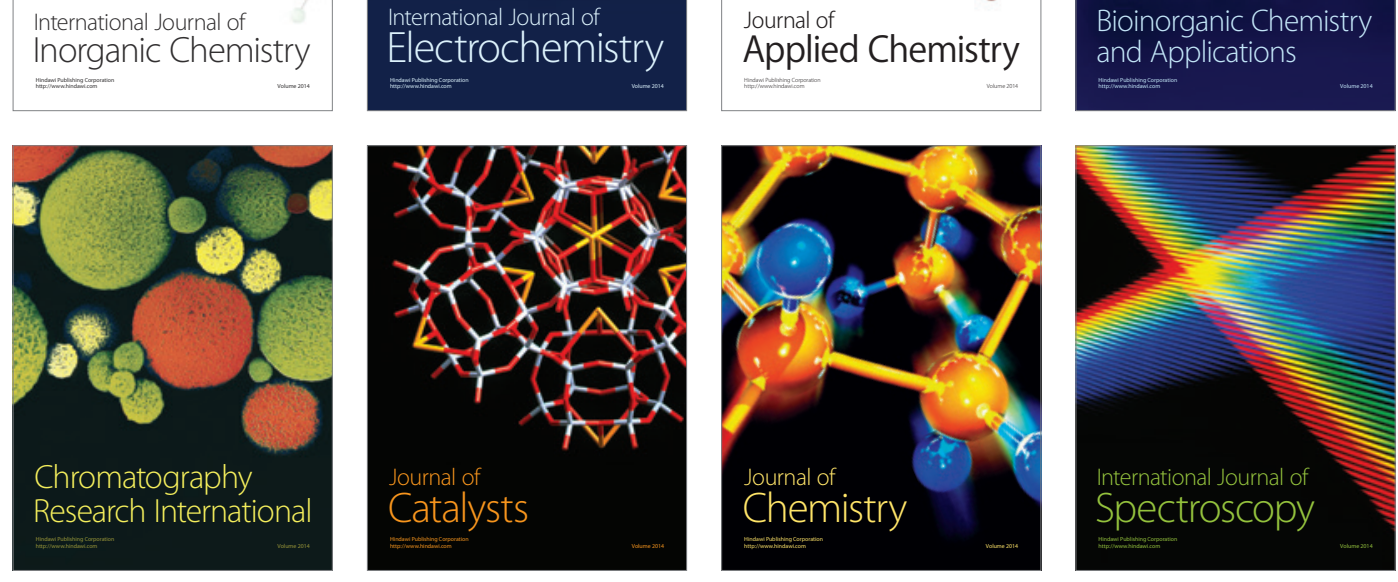